\title{
INTERVIEW
}

For reprint orders, please contact: reprints@futuremedicine.com

\section{A long career in gastrointestinal oncology}

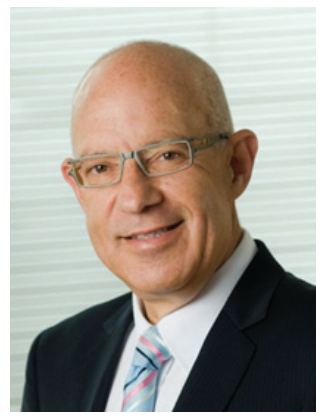

JOHN R ZALCBERG* SPEAKS TO STELLA BENNETT, COMMISSIONING EDITOR: Professor John Zalcberg was the Director, Division of Cancer Medicine, at the Peter MacCallum Cancer Centre in Melbourne, Australia for 17 years. In 2014, he took up the position of Head of the Cancer Research Program in the School of Public Health and Preventive Medicine at Monash University where he is involved in setting up a number of national clinical quality registries in cancer. After earning a Bachelor of Medicine and a Bachelor of Surgery from the University of Melbourne he did a PhD in cancer immunology. He is immediate past Chair of the Board of the Australasian Gastrointestinal Trials Group after serving in this role for over 15 years. He is the current Co-Chair of the Cancer Drugs Alliance, an organization which advocates for improved access to new cancer drugs for patients and also the Chair of the Australian Clinical Trials Alliance. This organization is involved in advocating for embedding clinical research into routine clinical practice in order to improve the quality of healthcare delivery. He is also a Board Member of the Australian Red Cross Blood Service. A past Board Member of the NSW Cancer Institute, past President of the Clinical Oncological Society of Australia, and a past Member of the Consultative Council of the Victorian Cancer Agency, he has received a Medal of the Order of Australia Award, the 2011 Cancer Achievement Award from the Medical Oncology Group of Australia and the 2014 'Tom Reeve Award for Outstanding Contributions to Cancer Care' from the Clinical Oncology Society of Australia. Professor Zalcberg's clinical research interests include gastrointestinal cancer and healthcare outcomes. He was a Principal Investigator for the EORTC advanced GIST trial in Australia, remains active in numerous trials in gastrointestinal malignancies and continues an active clinical practice in gastrointestinal cancer. He has published more than 240 articles in peer-reviewed journals.

Q You earned your PhD in cancer immunology. What led to your early interest in cancer immunology \& how did this develop into a more specific interest into gastrointestinal/colorectal cancers?

I did a $\mathrm{PhD}$ in human immunology, having spent some time as a resident and fellow in the hematology service. I was struck by the enormous needs of patients, particularly with acute leukemia, since those were the patients that spent a lot of time in hospital. I had grown up with the view that the immune system was somehow important in what happened to tumors, and ironically having done my $\mathrm{PhD}$ in human

\section{Colorectal Cancer}

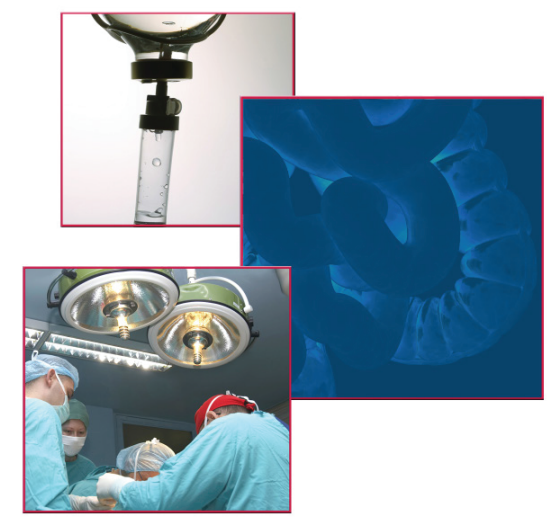

\section{KEYWORDS}

- gastrointestinal oncology

- personal journey

${ }^{*}$ Cancer Research Program, School of Public Health \& Preventive Medicine (SPHPM), Faculty of Medicine, Nursing

\& Health Sciences, Monash University, Level 5 The Alfred Centre, 99 Commercial Rd, Melbourne, Vic. 3004, Australia;

Tel.: +61 39903 0388; Fax: +61 39903 0556; john.zalcberg@monash.edu

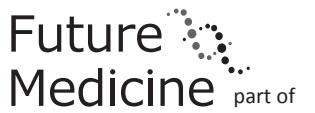


immunology was convinced at the end that the immune system had nothing to do with cancer. That was not to say the immune system could not be manipulated to treat or control cancer, but I was convinced that the old argument that the immune system was important in the cause of cancer was based on an understanding of viruses and not related to what was happening in the case of malignant diseases. As I said, ironically, I have had to retract these ideas now as the new generation of drugs which modify the immune system and interfere with immune check points come into practice. In fact, these have led to quite dramatic cancer control. So, I guess with my $\mathrm{PhD}$ I learnt to look at data and reach conclusions, but at least I learnt that I had a lot more to learn.

So, to come back to the question of why I got interested in colorectal cancer in particular and gastrointestinal cancer more broadly. I did a fellowship at the Princess Margaret hospital in Toronto and during that time Folinic acid was just being added to fluorouracil (5-FU) to treat patients with advanced colorectal cancer. For the first time, we started to see people whose tumors shrank. When I think back now, that was 20 or 30 years ago and we have moved on enormously since then, but when you see a major change, and major is a strong word here, because it was not dramatic, but it felt dramatic, that suddenly, we were seeing people that were actually getting better. Their tumors shrank, and they felt better. We did not know then that they lived longer, but as a young Fellow it certainly left a lasting impression. In fact, I came back from that fellowship and actually tried to set up a clinical trial with 5-FU and folinic acid as adjuvant therapy. That was, I guess, the beginning of my interest in gastrointestinal (GI) cancer. Most of my research in colorectal cancer, has been done through the Australasian Gastrointestinal Trials Group [1]. In fact, in facilitating clinicians to come together to do that adjuvant study, the nidus that led to the development of the Australasian Clinical Trials Group, which then became ultimately the Australasian Gastrointestinal Trials Group was formed. The purpose of that group - it was an academic cooperative trials group, like many such groups around the world - was to ask our community, both clinicians and later on consumers as well to consider what were the clinically important questions. When they saw patients on a day-to-day basis, what were the areas of clinical medicine that they were unable to make decisions about because of lack of evidence. That was our role to bring those questions to the fore, to try and answer clinically important questions through clinical trials research and to move the field forward. Over the almost 20 years that I was involved - and I am still involved, though no longer on the Board - we conducted a number of trials not only in advanced colorectal cancer but also in early colorectal cancer, so we did trials of adjuvant therapy as well in advanced disease. And, of course, we were also involved in trials of new approaches in other parts of the GI tract.

Q You have been a member of the Consultative Council of the Victorian Cancer Agency since 2007. What are your main responsibilities here?

The Victorian Cancer Agency [2] was set up by the Victorian government to help develop a comprehensive research program in cancer across the state. The state of Victoria has about 5.5 million people (June 2014 [3]). I was fortunate enough to be appointed by the Minister of Health to the Council. I came off that a couple of years ago, so I am no longer a member of that Council, but the Council continues - I think we were very pleased in the initial years to develop Fellowships, both in supportive care as well as biological, fundamental research, and of course clinical research. I was involved in chairing a clinical trials subcommittee as we were very keen to support clinical trials networks and clinical trials that were initiated in Victoria. So, the Victorian Cancer Agency continues, and it is part of a complex spectrum of various funding agencies within Australia that help support cancer research.

Q As a clinician, how would you say that the standard of care changed for patients with Gl cancer?

I think the standards of care have changed enormously over the last few years, and indeed over the last decade. I think, first, there is a much better understanding of the role of early detection, and a much better understanding of the multidisciplinary nature of cancer control, rather than treatment decisions being the domain of any one speciality. There is an increasing understanding of the importance of supportive care and that includes nutritional support and providing psychological support and communication. Overall, there have been a number of changes, and fortunately in almost every tumor of the GI tract, we are able to say that current treatments are better today than they were 5 years ago, and better 
in turn then than they were 5 years before that. I think that there are still lots of challenges; in Victoria, $65 \%$ or more of people diagnosed with colon cancer are alive 5 years later, but nevertheless we still have a significant burden of disease to cope with. We still have a number of patients who die prematurely of colorectal cancer, and of course Australia is no different to any other part of the world with the terrible outcomes that occur with pancreatic cancer, even when it appears to be localized. So, I think the research that is going on is enormously important. The other thing I should mention is the changes that have occurred in the understanding of the natural biology of the disease and in particular the role of the genetic changes that causes cancer to occur and is so influential in how drugs or other treatments work. So undoubtedly there have been changes in almost every sphere of GI cancer. It depends a little on which type of tumor you are talking about, to the extent of those changes and the magnitude of the benefit, but I do not underestimate the challenge of what lies ahead of us and how much more work we have got to do.

\section{Q Do you think that the doctor-patient} relationship has become more important now, \& if so, why?

Personally, I have always felt that the doctorpatient relationship has been important. My mantra, or motto if you like, has always been 'do unto others as you would have done unto yourself'. On the other hand, I think that is quite easy to say and hard to practice. I think the doctor-patient relationship was always critical, and it remains critical. I think there are individual styles around how people relate to patients with respect to fundamental issues like communicating bad news, communicating hope and providing relief from suffering - in terms of the relationship rather than the actual treatments administered. There are different ways of doing that, and different patients need different things, and different doctors do things in different ways, but I do not think that the doctor-patient relationship has ever been unimportant and I think it remains paramount.

\section{Q You have received numerous awards} during your career so far; what would you say has been your biggest achievement to date? The thing that I feel is most important is that we always try to consider the role of evidence and the role of research in the healthcare system, and understand that by conducting research we improve the quality of healthcare. I am not sure that I could say that is an achievement of mine, I would say that is an achievement of the wider academic community in bringing research into healthcare. We are increasingly finding that policy makers and governments are starting to understand this agenda. It is not research for research's sake, it is research embedded in the health system, which leads to a better health system, and ultimately to the benefit of the community as a whole. I have been part of that movement to bring research into healthcare; I am only one part of it, a small cog in large wheel, but I am proud of being a part of that process.

Q The cost \& availability of drugs, particularly cancer drugs, has been quite a hot topic recently. What are your thoughts on the debate regarding costs of drugs \& pharma company responsibility versus the availability of treatment for patients?

The availability of drugs is really an important issue, particularly becoming critical as the types of drugs becoming available are increasingly making not small differences, but dramatic differences to people's lives. I was involved in the Phase III study of imatinib when it was first used in clinical trials for the management of patients with advanced gastrointestinal stromal tumors. I think it was the third patient we treated on that trial, but that patient was admitted to ICU because they were so unwell, and yet walked out of ICU on this drug. All I am trying to illustrate from that is that some of the new generations of drugs are not just producing incremental benefits but they are producing substantial, life-changing benefits. My view is that everyone should have access to those drugs if they are living in a developed country, and Australia is a developed country. I am very concerned that many drugs that are available overseas are not available in Australia, or that there is a substantial time difference in terms of their availability to Australians. The notion, for me, that wealthy people - and I mean really quite wealthy as opposed to middle class - can afford to access these drugs when they are on the market elsewhere in the world, but the majority of Australians cannot, is of great concern to me, personally. It is of great concern to me as a clinician, so much so that I am now the Co-Chair of an organization in Australia called the Cancer Drugs Alliance [4]. 
We are a one-agenda organization involving clinicians, consumers and pharma, and we are advocating for this one issue: to provide equitable and timely access to new cancer drugs to Australians. In fact, on the 27 February 2015, submissions closed to a Senate Inquiry on Access to Cancer Drugs, and I am really hopeful that there will be an overwhelming response as the community speaks out and indicates its concern over the fact that many patients cannot access these drugs in a timely manner. I do think it is a major issue. In terms of responsibility of pharma versus others, I think it is a difficult question and certainly I acknowledge the concerns around whether this is all about pharma profits. On the other hand, drugs are not manufactured without pharmaceutical companies. Almost without exception, no one is able to develop a drug unless they are a biotechnology/pharmaceutical company. So, that is just the way life is. Drugs can be discovered by universities or academic organizations, but in the end they need the resources of the pharmaceutical company to be developed, and that requires that those companies can achieve a return on investment. That is the system we live in. Rather than say whether pharma is taking too much, or too little, or whatever the case may be, my focus has always been on the patient. It is up to governments and pharma to negotiate the cost of drugs, and I agree we have community responsibilities, but our primary responsibility I believe, as clinicians, is to the patient. Patients need to know what drugs are available, and patients ultimately need to be able to access them in a developed country.

\section{Q How would you like to see the field of colorectal cancer research develop in the next} 5-10 years?

I think the field is moving very much in the direction that, I hope everyone would agree, is the best way forward. That is, increasing and continued research into the biology of tumors, molecular markers, the immune environment and so forth. There remains a strong interest from pharmaceutical companies and biotechnology companies in defining appropriate targets and testing those targets. I think one area that is absolutely critical is that we find a way of allowing different companies to work together. That is already happening, I believe, in some tumor types. It has not happened to the same extent in colorectal cancer as yet, but being able to combine drugs and different companies so that we can work out the best way of using those drugs I think is going to be a really important way forward because increasingly it's becoming apparent that it is is not going to be just one drug that suddenly changes the game, it is going to be combinations. It is going to be different sequences. It is going to take a range of different strategies, and that will require collaboration not only within academia, but collaboration with industry. And, hopefully, everybody wins, first the patient, but equally the academics and the industry itself.

\section{Q Finally, do you have any current projects or research you would like to share with our readers?}

I am currently head of the cancer research program within the School of Public Health and Preventive Medicine within the Faculty of Medicine, at Monash University [5], and we have started setting up a Cancer Registry program. That registry program is a bit different to what people might normally think of as a registry. The word 'registry' means different things to different people. The registries that we are interested in are clinical quality registries, that is, registries that extract data from existing clinical databases and measure the practice of healthcare professionals and outcomes of care against international evidence-based guidelines. I think this is a very powerful way to improve the quality of healthcare. It allows institutions and practices to benchmark, and in doing that benchmarking, allows us to understand the reasons for variation in process, practice and outcomes. Once you understand variation, what we will have is what we are calling a 'self-improving health system'. The way this works is that once there is variation in outcomes due to things like uncertainty in the evidence, or lack of evidence, conflicting evidence, contradictory evidence and so forth - that is, it becomes apparent that variation is due to an evidence gap, that then leads to the question of 'let's do a clinical trial and answer the question'. So, if we do not know whether A or $\mathrm{B}$ are preferable treatment options and there is evidence for $A$ and there is evidence for $B$, let's compare A and B. A and B can be surgery and radiation, or chemotherapy or combinations thereof. Once you do that, then you develop new evidence. That evidence then becomes implemented, practice patterns assessed and you then measure the effect of that new evidence in the 
health system. You again see variation, so that leads to the next trial. I have been fortunate to be the interim chair of the Australian Clinical Trials Alliance [6], and the mission here is to basically propagate a model of healthcare based on the selfimproving health system. Understanding that the best way we can improve healthcare is through clinical research. The networks that conduct these studies need to be embedded in the health system. The registries and coordinating centres also need to be embedded in the health system and their substantial infrastructure requirements addressed. In so doing, we will end up with a more efficient, more productive healthcare (system) and better outcomes for patients.

\section{References}

1 Australasian Gastrointestinal Trials Group. http://agitg.org.au

2 Victorian Cancer Agency. www.victoriancanceragency.org.au

\section{Disclaimer}

The opinions expressed in this interview are those of the interviewee and do not necessarily reflect the views of Future Medicine Ltd.

\section{Financial \& competing interests disclosure}

$J R$ Zalcberg has received travel support, research support and Chairs various Advisory Boards for a number of pharmaceutical compaines. JR Zalcerberg has no other relevant affliations or financial involvement with any organization or entity with a financial interest in or financial conflict with the subject matter or materials discussed in the manuscript apart from those disclosed.

No writing assistance was utilized in the production of this manuscript. www.abs.gov.au/ausstats/abs@.nsf/mf/3101.0

4 Cancer Drugs Alliance. www.cancerdrugsalliance.org.au
5 School of Public Health and Preventative Medicine at the Monash University. www.med.monash.edu

6 Australian Clinical Trials Alliance. www.clinicaltrialsalliance.org.au 